\title{
Progesterone effects during sequential hormone replacement therapy
}

\author{
Lotta Andréen, Mari Bixo, Sigrid Nyberg, Inger Sundström-Poromaa and Torbjörn Bäckström \\ Department of Clinical Sciences, Obstetrics and Gynecology, Umeå University, Umeå, Sweden \\ (Correspondence should be addressed to T Bäckström, Department of Obstetrics and Gynecology, University Hospital, S-901 87 Umeå, Sweden; \\ Email: torbjorn.backstrom@obgyn.umu.se)
}

\begin{abstract}
Objective: The aim was to investigate the effect on mood and the physical symptoms of two dosages of natural progesterone and a placebo in postmenopausal women with and without a history of premenstrual syndrome (PMS).

Design: A randomized, placebo-controlled, double-blind, crossover study was performed.

Method: Postmenopausal women $(n=36)$ with climacteric symptoms were recruited. They received $2 \mathrm{mg}$ estradiol continuously during three 28-day cycles. Vaginal progesterone suppositories with $800 \mathrm{mg} /$ day, $400 \mathrm{mg} /$ day, or placebo were added sequentially for 14 days per cycle. Daily symptom ratings using a validated rating scale were kept.

Results: Women without a history of PMS showed cyclicity in both negative mood and physical symptoms while on $400 \mathrm{mg} /$ day progesterone but not on the higher dose or the placebo. Women without a history of PMS had more physical symptoms on progesterone treatment compared with placebo. Women with prior PMS reported no progesterone-induced symptom cyclicity.

Conclusion: In women without prior PMS natural progesterone caused negative mood effects similar to those induced by synthetic progestogens.
\end{abstract}

European Journal of Endocrinology 148 571-577

\section{Introduction}

It is well known that sequential hormone replacement therapy (HRT) causes cyclicity in mood and physical symptoms similar to those symptoms encountered during ovulatory cycles and in premenstrual syndrome (PMS). It seems plausible to conclude that it is the addition of synthetic progestogens in HRT that provokes these negative mood symptoms $(1-5)$.

One major question, however, is whether or not natural progesterone has the same effect on mood as synthetic progestogens (6). In laboratory animals, some of progesterone's metabolites, i.e. $3 \alpha-\mathrm{OH}-5 \alpha$-pregnan-20-one (allopregnanolone) and $3 \alpha-\mathrm{OH}-5 \beta-$ pregnan-20-one (pregnanolone), have barbiturate- and benzodiazepine-like effects mediated through their binding to the gamma aminobutyric acid $\left(\mathrm{GABA}_{\mathrm{A}}\right)$ receptor complex in the brain, thereby eliciting hypnotic, anxiolytic, and anti-epileptic effects $(7,8)$. In humans, progesterone can, in large doses, induce anesthesia, and this effect is mediated via the metabolism of progesterone to allopregnanolone and pregnanolone $(8,9)$. Similarly, the acute anxiolytic effect of progesterone in laboratory animals is mediated through its conversion to allopregnanolone, active on the $\mathrm{GABA}_{\mathrm{A}}$ receptor (10).

A paradox has emerged as all synthetic progestogens tested so far induce negative mood effects in humans, while natural progesterone seems to have the opposite effect on mood, at least in animal experiments. So far, in humans, most studies on mood and natural progesterone have focused on treating PMS. These controlled trials have been unable to confirm any superiority of progesterone to placebo in terms of the lessening of PMS symptoms $(11,12)$. Instead, there are indications that natural progesterone is involved in negative mood changes. The recurrence of physical and psychological symptoms in the late luteal phase in women with PMS is related to increased progesterone serum concentrations during this period (13). Between menstrual cycles, an intra-individual worsening of symptoms is related to higher progesterone serum concentrations (14). An important question therefore arises: is progesterone qualitatively different from progestogens in its ability to influence mood or are the reported differences in symptom-provoking effects due to differences in progesterone/progestogen dose? To our knowledge, natural progesterone has not previously been investigated with respect to its possible 
mood-improving or -deteriorating effects in postmenopausal women on sequential HRT.

It has been reported that women with a history of PMS, during their fertile life, respond with less positive and more negative mood symptoms compared with controls under treatment with progestogens $(3,5)$. However, women with PMS seem to be less sensitive to the sedative effects of pregnanolone, a progesterone metabolite, and benzodiazepines compared with controls $(15,16)$. In terms of negative mood symptoms, they seem to respond more strongly to oral contraceptives than women who do not have PMS (17). Thus, a history of PMS may be of importance for the severity of reaction to progesterone in postmenopausal women (3). This motivates recording the presence of PMS during fertile life in postmenopausal women.

The objective of this randomized, double-blind, placebo-controlled study was to investigate if the addition of vaginal progesterone to estrogen treatment induces effects on mood and physical symptoms and whether or not these are dose-dependent. Furthermore, the study aimed to evaluate whether a history of PMS influences the potential adverse mood effects induced by vaginal progesterone.

\section{Materials and methods}

\section{Subjects}

Thirty-six women with climacteric symptoms were recruited and randomly assigned to treatment in a double-blind, crossover study. Subjects were more than 6 months postmenopausal and had not used any HRT for the past 3 months prior to inclusion in the study. None were receiving any steroid treatment, and all had an intact uterus and no contraindications to HRT. They had no history of psychiatric illness and had not been treated with psychopharmacologic drugs within the past 6 months. Subjects with ongoing psychiatric illness were excluded by the use of PRIMEMD. PRIME-MD has been developed to help primary care physicians to screen, evaluate, and diagnose mental disorder. This diagnostic tool is constructed to conform to Diagnostic and Statistical Manual of Mental disorders, Fourth edition (DSM-IV) criteria and has been validated for use in a primary care setting (18). PRIME-MD is fully described elsewhere (18). The agreement between PRIME-MD and independent psychiatric diagnoses guided by a structured interview is generally excellent across modules, with an overall accuracy of $88 \%$ (18). Before inclusion, patients gave their written consent and agreed to keep a daily record of their symptoms. They also underwent a physical and gynecological examination, including a routine vaginal ultrasonography.

The study included women with and without a history of PMS. Premenstrual symptoms during fertile life were defined by a retrospective report of mood deterioration prior to menstruation which decreased and disappeared within 4 days after the onset of menstrual bleeding. The influence of PMS symptoms on daily life was graded, and women whose family relations, social activities, or work were negatively affected by the symptoms were considered to have a history of PMS.

\section{Study design}

The effect of two different progesterone doses on symptom cyclicity was evaluated in a randomized, placebocontrolled, double-blind, crossover design. The women were divided into three groups and treated for three 28-day cycles. Estradiolvalerat at a dose of $2 \mathrm{mg}$ (Apoteket $\mathrm{AB}$, Stockholm, Sweden (the national pharmacy company)) was given continuously throughout the study period. Progesterone vaginal suppositories were added on days 15-28 of each cycle. One group started the sequential treatment with $800 \mathrm{mg} /$ day progesterone, the second group with $400 \mathrm{mg} /$ day progesterone, and the third group with placebo vaginal suppositories. All suppositories were given as $400 \mathrm{mg}, 200 \mathrm{mg}$, or placebo twice a day. A crossover to a new treatment was carried out after each cycle. The two progesterone doses chosen are the two pharmaceutical preparations available in Sweden at present, and it has been shown that there is a significant difference in progesterone serum concentrations between the two doses (19). The vaginal formulation was a waxy suppository containing progesterone in a base of semi-synthetic glycerides produced from hydrogenated vegetable oil by interesterification.

The vaginal pessaries were prepared by Apoteket AB, Production and Laboratories. The suppositories were made to appear identical. Packing and randomization were done by the pharmacy at Umeå University Hospital.

In women with climacteric symptoms, estrogen is known to decrease the vasomotor symptoms during the first month of treatment. In parallel with the improvement in vasomotor symptoms there is an increase in well-being due to relief of symptoms. To avoid interference with the mood changes related to improvements in vasomotor symptoms, a run-in cycle with an ordinary sequential HRT treatment was given in order to treat the vasomotor symptoms before the study proper started (20). Therefore, the study began with a 28-day run-in cycle where the patients were treated with $2 \mathrm{mg}$ estradiolvalerat daily and $10 \mathrm{mg}$ medroxyprogesterone (MPA) on days 15-28 of the cycle. The drawback of this procedure is that all cycles following a progestogen treatment will have a 3- to 4-day period at the beginning of the next cycle when the symptoms from the previous cycle decline (3).

The primary outcome measure was the daily symptom ratings made by the patients throughout the study. We used a modified form of the cyclicity diagnoser ((CD) Diagnoskonsuelt, Umeå, Sweden), an instrument 
for diagnosing cyclic symptoms that has been validated for the diagnosis of PMS (21) but also used to evaluate HRT-related symptom changes in postmenopausal women (3). The CD included four physical symptoms (breast tenderness, hot flushes, abdominal bloating, and withdrawal bleeding) and seven psychological symptoms (cheerfulness, friendliness, libido, anxiety/tension, irritability, fatigue, and depression). The effects on daily life caused by symptoms were graded using a Likert scale (tick boxes) from 0 to 8 , where 0 indicates complete absence of a particular symptom and 8 represents the maximum severity of the symptom. One scale step is enough to detect a difference in mood experience, as shown in a study of symptom severity in women with PMS (21). The Umeå University Ethical Committee and the National Medical Products Agency approved the study design.

A gynecologist saw the patients twice, at their inclusion and at the termination of the study (16 weeks). During the study, patients made scheduled visits to a research nurse at 4,8 , and 12 weeks. Weight, blood pressure, and gynecological examination including a routine vaginal ultrasonography were followed up after 16 weeks.

\section{Hormone assays}

Once every cycle, during the last week of progesterone treatment, blood samples for progesterone and estradiol analyses were collected immediately before the vaginal administration of progesterone in the morning. Two hours later a new blood sample for progesterone analysis was taken. Measurements of plasma progesterone and estradiol were taken using Delfia progesterone and estradiol kits (Wallac Oy, Turku, Finland), a fluoroimmunoassay, according to the manufacturer's instructions.

\section{Statistics}

Symptoms were analyzed separately and in clusters of related symptoms in an intention-to-treat manner. Related symptoms were grouped in clusters as mean scores of summarized symptoms: 'negative mood symptoms,' i.e. tension, irritability, and depression; 'positive mood symptoms,' i.e. cheerfulness and friendliness; and 'physical symptoms,' i.e. breast tenderness and bloating.

The cyclicity of each symptom or symptom group was investigated using two-way analysis of variance (ANOVA) with repeated measures. Independent variables were cycle phase, estrogen-phase (E-phase) treatment days $11-15$ vs estrogen/progesterone-phase (E/P-phase) treatment days 24-28, and cycle day. The effects of the different doses of progesterone and of PMS history on summarized negative, positive, and physical symptoms were analyzed by ANOVA with repeated measures. Least significant difference test was used as a post hoc method when applicable. Independent factors in these analyses were patient group
(PMS vs non-PMS), progesterone dose (placebo, $400 \mathrm{mg}$, or $800 \mathrm{mg}$ ), and progesterone day (days 15-28). Demographic data are shown in mean values and range. The SPSS statistical package was used for the analyses. $P<0.05$ was considered significant.

\section{Results}

\section{Sample description}

Thirty-one women completed the study. Of these, 13 had a history of PMS and 18 had no history of PMS. Of the 36 women who were originally included in the study, two dropped out during the study course (one because of heavy withdrawal bleeding and breast tenderness, one because of nausea). Three women were excluded (one because of a major life event, two because of failure in medicine intake). One of the 31 women was not able to participate in giving blood samples. Demographic data of the study group are shown in Table 1.

\section{Symptom cyclicity}

Cyclicity in symptoms was evaluated in the whole study group. The best period, when mood was at its highest and physical symptoms at their lowest, occurred during mid cycle (days 11-15). The worst period peaked during the late progesterone phase (days 24-28). Of all the symptoms on the CD scale, only physical symptoms displayed a significant difference between the E-phase and E/P-phase. The cyclicity of physical symptoms was evident during treatment cycles with progesterone at $800 \mathrm{mg} /$ day and $400 \mathrm{mg} /$ day $(\mathrm{F}(1,30)=7.64 ; P<0.05$ and $\mathrm{F}(1,30)=5.17 ; P<0.05$ respectively). During the placebo treatment no cyclical changes were noted. There was no significant change in intensity of the symptoms over time throughout the study course.

\section{Symptom cyclicity in women with and without a history of PMS}

During cycles with $400 \mathrm{mg}$ /day progesterone women without a history of PMS showed a significant increase in negative mood and physical symptoms during the E/P-phase compared with the E-phase $(\mathrm{F}(1,17)=$ 5.92; $P<0.05$ and $\mathrm{F}(1,17)=5.09 ; P<0.05$ respectively) (Figs 1 and 2). Scores of breast tenderness were the only symptom that showed significant cyclicity

Table 1 Demographic data of the study group.

\begin{tabular}{ll}
\hline Age (mean years and range) & $52(44-60)$ \\
Working (\%) & 97 \\
Married (\%) & 65 \\
Former users of oral contraceptives (\%) & 84 \\
Previous pregnancy (\%) & 90 \\
Hot flushes (\%) & 90 \\
\hline
\end{tabular}



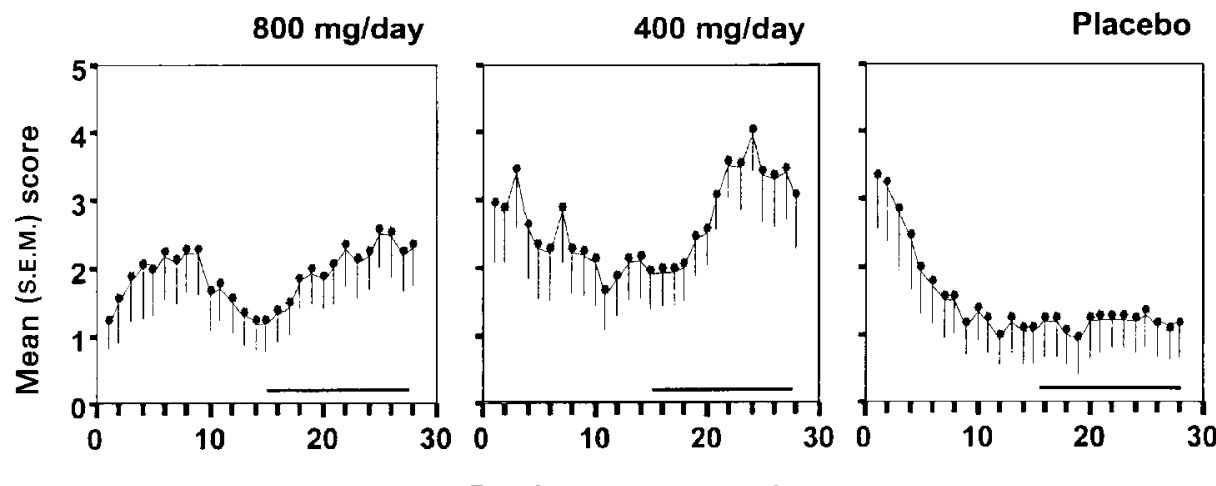

Day in treatment cycle

Figure 1 Mean (S.E.M.) summarized physical symptom scores (breast tenderness+abdominal bloating) in women without a history of PMS $(n=18)$ treated in a crossover design. Left panel: continuous treatment with $2 \mathrm{mg}$ estradiolvalerat $+800 \mathrm{mg} / \mathrm{day}$ progesterone vaginal pessary, days 15-28. Center panel: continuous treatment with $2 \mathrm{mg}$ estradiolvalerat+400 mg/day progesterone vaginal pessary, days 15-28. Right panel: continuous treatment with $2 \mathrm{mg}$ estradiolvalerat+a placebo pessary, days 15-28. During cycles with $400 \mathrm{mg} /$ day progesterone added (center panel), women without a history of PMS showed a significant cyclicity in physical symptoms between E-phase and E/P-phase $(\mathrm{F}(1,17)=5.92 ; P<0.05)$.

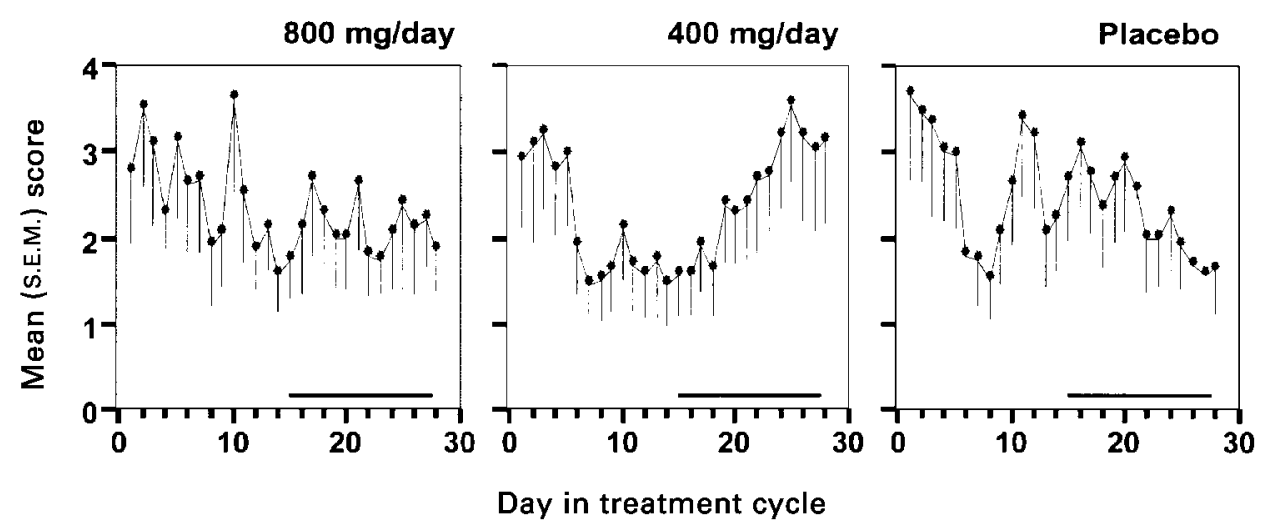

Figure 2 Mean (S.E.M.) summarized negative mood scores (irritability+tension+depression) in women without a history of PMS ( $n=18$ ) treated in a crossover design. Left panel: continuous treatment with $2 \mathrm{mg}$ estradiolvalerat+800 mg/day progesterone vaginal pessary, days 15-28. Center panel: continuous treatment with $2 \mathrm{mg}$ estradiolvalerat $+400 \mathrm{mg} /$ day progesterone vaginal pessary, days $15-28$. Right panel: continuous treatment with $2 \mathrm{mg}$ estradiolvalerat+a placebo pessary, days $15-28$. During cycles with $400 \mathrm{mg} / \mathrm{day}$ progesterone added (center panel), women without a history of PMS showed a significant cyclicity in negative mood symptoms between E-phase and E/P-phase $(\mathrm{F}(1,17)=5.09 ; P<0.05)$.

during the cycle with $800 \mathrm{mg} /$ day progesterone in women without prior PMS (see Table 2 for results).

Women with prior PMS reported overall significantly lower scores of positive symptoms in both E- and E/P-phases during all treatments $(\mathrm{F}(1,91)=11.3$; $P<0.005)$ compared with women with no history of PMS. Women with prior PMS displayed no significant cyclicity of any symptom on the CD scale.

\section{Difference in symptom severity within women between progesterone at $400 \mathrm{mg} / \mathrm{day}$, $800 \mathrm{mg} / \mathrm{day}$, and placebo}

Women without a history of PMS had significantly more physical symptoms $\quad(\mathrm{F}(2,32)=8.52 ; \quad P<0.001)$ during the E/P-phase when treated with $400 \mathrm{mg} /$ day progesterone compared with treatment with $800 \mathrm{mg} /$ day or placebo. The mean (s.E.M.) score of physical symptoms during progesterone at $400 \mathrm{mg} /$ day was 3.5 (0.68) compared with $2.4(0.52)$ during $800 \mathrm{mg} /$ day $(P<0.05)$, and $1.1(0.45)$ during placebo treatment $(P<0.001)$.

\section{Progesterone and estradiol}

Progesterone serum concentrations were significantly increased $2 \mathrm{~h}$ after the application (C high) compared with the concentration before the application (C low) during treatment with progesterone at $800 \mathrm{mg} /$ day and $400 \mathrm{mg} /$ day $(\mathrm{F}(1,29)=28.2 ; \quad P<0.001$ and 
Table 2 Mean (S.E.M.) symptom scores during 5 days of estradiol (E) treatment and 5 days of estradiol+progesterone (E+P) treatment in cycles treated with progesterone $(P) 800 \mathrm{mg}, 400 \mathrm{mg}$, or placebo. The table shows the results from patients without a history of PMS studied in a randomized, double-blind, crossover manner.

\begin{tabular}{|c|c|c|c|c|c|c|c|c|c|c|c|c|}
\hline & $\mathbf{E}$ & $\begin{array}{c}\mathbf{E}+\mathbf{P} \\
(800 \mathrm{mg})\end{array}$ & $\mathbf{F}$ & $\boldsymbol{P}$ & $\mathbf{E}$ & $\begin{array}{c}\mathbf{E}+\mathbf{P} \\
(400 \mathrm{mg})\end{array}$ & $\mathbf{F}$ & $\boldsymbol{P}$ & $\mathbf{E}$ & E+placebo & $\mathbf{F}$ & $\boldsymbol{P}$ \\
\hline Physical symptoms & $1.0(0.23)$ & $1.8(0.25)$ & 3.56 & 0.08 & 1.8(0.28) & $3.1(0.29)$ & 5.92 & 0.03 & $0.52(0.11)$ & $0.96(0.24)$ & 0.03 & n.s \\
\hline Ábdominal bloating & $0.64(0.18)$ & $0.40(0.11)$ & 0.05 & n.s & $0.78(0.14)$ & $1.0(0.11)$ & 3.53 & 0.08 & $0.30(0.07)$ & $0.60(0.15)$ & 0.79 & n.s \\
\hline Breast tenderness & $0.38(0.10)$ & $1.4(0.19)$ & 6.46 & 0.02 & $0.98(0.18)$ & $2.08(0.30)$ & 5.21 & 0.04 & $0.22(0.07)$ & $0.36(0.10)$ & 0.38 & n.s \\
\hline Negative symptoms & $1.6(0.30)$ & $2.4(0.53)$ & 0.14 & n.s & 1.6(0.32) & $2.5(0.43)$ & 5.09 & 0.04 & $2.5(0.45)$ & $2.1(0.38)$ & 1.38 & n.s \\
\hline Irritability & $0.54(0.15)$ & $0.70(0.19)$ & 0.07 & n.s & $0.38(0.10)$ & $0.83(0.18)$ & 2.34 & n.s & $0.82(0.18)$ & $0.96(0.19)$ & 0.76 & n.s \\
\hline Anxiety/tension & $0.66(0.15)$ & $0.82(0.22)$ & 0.02 & n.s & $0.69(0.16)$ & $0.80(0.16)$ & 4.64 & 0.05 & $0.66(0.20)$ & $0.58(0.13)$ & 0.14 & n.s \\
\hline Depression & $0.44(0.13)$ & $0.92(0.21)$ & 0.34 & n.s & $0.55(0.13)$ & $0.83(0.18)$ & 6.14 & 0.02 & $0.98(0.20)$ & $0.58(0.14)$ & 2.94 & n.s \\
\hline Positive symptoms & $11(0.45)$ & $10(0.46)$ & 0.19 & n.s & $11(0.39)$ & $11(0.56)$ & 1.78 & n.s & $10(0.50)$ & $11(0.47)$ & 1.39 & n.s \\
\hline Cheerfulness & $5.7(0.27)$ & $5.5(0.31)$ & 0.19 & n.s & $5.8(0.21)$ & $5.4(0.31)$ & 1.12 & n.s & $5.6(0.30)$ & $5.7(0.30)$ & 2.92 & n.s \\
\hline Friendliness & $5.1(0.32)$ & $5.0(0.30)$ & 0.00 & n.s & $5.0(0.29)$ & $5.4(0.27)$ & 1.24 & n.s & $4.8(0.32)$ & $4.9(0.31)$ & 0.27 & n.s \\
\hline Hot flushes & $0.24(0.09)$ & $0.40(0.11)$ & 0.56 & n.s & $0.42(0.12)$ & $0.48(0.13)$ & 4.39 & 0.05 & $0.16(0.07)$ & $0.28(0.14)$ & 0.62 & n.s \\
\hline Fatigue & 1.6(0.29) & 1.6(0.29) & 0.94 & n.s & $1.2(0.25)$ & $1.0(0.22)$ & 3.07 & n.s & 1.1(0.21) & 1.2(0.21) & 0.10 & n.s \\
\hline Libido & $1.4(0.24)$ & $1.7(0.29)$ & 0.06 & n.s & $1.5(0.26)$ & $1.4(0.27)$ & 0.65 & n.s & $1.7(0.23)$ & $1.6(0.27)$ & 0.57 & n.s \\
\hline Effects on daily life & $0.02(0.02)$ & $0.38(0.09)$ & 1.43 & n.s & $0.09(0.04)$ & $0.43(0.11)$ & 2.92 & n.s & $0.22(0.07)$ & $0.28(0.11)$ & 1.37 & n.s. \\
\hline
\end{tabular}

Statistics are based on two-way ANOVA with repeated measure $(\mathrm{df}=1,17)$. n.s, not significant.

$\mathrm{F}(1,29)=31.9 \quad P<0.001 \quad$ respectively). During treatment with $800 \mathrm{mg} /$ day, serum concentrations of progesterone were significantly higher both at $\mathrm{C}$ high and C low compared with $400 \mathrm{mg} /$ day $(\mathrm{F}(1,29)=17.0 ; \quad P<0.001$ and $\mathrm{F}(1,29)=22.3$; $P<0.001$ respectively). No differences in serum progesterone concentrations were seen between women with and without prior PMS or between the two samples during placebo treatment. Mean serum concentrations of progesterone and estradiol during the different treatments are shown in Table 3.

\section{Discussion}

The main finding of this study was that women without a history of PMS showed a significant cyclicity in negative mood and physical symptoms during treatment with $400 \mathrm{mg} /$ day progesterone. The women felt worse during the estradiol/progesterone period compared with the estradiol only period. These cyclical changes were not seen during treatment with the higher dose of progesterone ( $800 \mathrm{mg} /$ day) or placebo. Women with prior PMS reported lower scores of positive mood symptoms compared with women without a history of PMS, but they reported no cyclical mood changes or cyclicity in physical symptoms.

We have not been able to confirm the hypothesis that the mood-deteriorating effects of progesterone are different from those induced by progestogens (6). Instead, we have shown that negative mood may be intensified during progesterone treatment in postmenopausal women in a similar way as with progestogens. There are now a number of studies showing a relationship between addition of a progestogen to HRT and appearance of negative mood and physical symptoms (1-5). A similar relationship also exists between the rise in progesterone concentration during the luteal phase of the menstrual cycle and the development of negative mental symptoms in women with PMS (14). The effect of progesterone shown in the present study is therefore not principally different from that which has been shown with progestogens and what happens during the menstrual cycle.

Table 3 Mean (S.E.M.) of plasma progesterone and estradiol concentrations. C low = nadir concentration sample just before adding the next pessary about $12 \mathrm{~h}$ after the previous application. $\mathrm{C}$ high $=$ sample taken $2 \mathrm{~h}$ after administration of the vaginal pessary.

\begin{tabular}{|c|c|c|c|}
\hline & $\begin{array}{c}\text { C low } \\
(\mathrm{nmol} / \mathrm{l})\end{array}$ & $\begin{array}{l}\text { C high } \\
(\mathrm{nmol} / \mathrm{l})\end{array}$ & $\begin{array}{c}\boldsymbol{P} \text { value } \\
\text { (C low vs } \mathrm{C} \text { high) }\end{array}$ \\
\hline Placebo progesterone & $1.04(0.15)$ & $0.75(0.16)$ & 0.638 \\
\hline Progesterone (400 mg) & $17.0(2.18)^{a}$ & $30.0(3.12)^{b}$ & 0.000 \\
\hline Progesterone (800 mg) & $26.8(3.47)^{a}$ & $40.9(3.99)^{b}$ & 0.000 \\
\hline Estradiol during placebo & $0.31(0.04)$ & - & - \\
\hline Estradiol during progesterone $(400 \mathrm{mg})$ & $0.33(0.05)$ & - & - \\
\hline Estradiol during progesterone $(800 \mathrm{mg})$ & $0.38(0.04)$ & - & - \\
\hline
\end{tabular}

a $400 \mathrm{mg}$ vs $800 \mathrm{mg} \mathrm{C}$ low $\mathrm{F}(1,29)=22.3 ; P<0.001$.

${ }^{\mathrm{b}} 400 \mathrm{mg}$ vs $800 \mathrm{mg} \mathrm{C}$ high $\mathrm{F}(1,29)=17.0 ; P<0.001$. Analysis method was ANOVA with repeated measure. 
Another finding in our study is that only when given the lower dose of progesterone do women without a history of PMS respond with cyclicity in their symptoms. The higher dosage of $800 \mathrm{mg} /$ day and the placebo treatment were not associated with symptom cyclicity. A similar pattern was seen in a study in which 10 and $20 \mathrm{mg}$ MPA were compared in postmenopausal women during sequential HRT. Women in that study responded with more negative mood symptoms to the lower dose of MPA compared with the higher dosage (22). Furthermore, oral contraceptives with a lower progestogen content have been reported to cause more negative mood changes compared with a compound with a higher progestogen content (22).

There is a contradiction between the evidence that high dosages of progesterone metabolites in animal experiments are anxiolytic while a low dose of progesterone, as in the present study, appears to have an anxiogenic or depressant effect in humans. However, this anxiogenic effect seems to be lost with a higher dose of progesterone. These findings may indicate a dual effect of progesterone. Possibly low doses of progesterone are anxiogenic, whereas high doses have less anxiogenic effects or may even be anxiolytic. These hypotheses are supported by data from animal experiments in which low physiological doses of progesterone metabolites cause aggressive and aversive behavior but high dosages are inert or anxiolytic $(23,24)$. In addition, during short-term treatment with physiologically relevant doses of progesterone in rats, a connection exists between progesterone-induced anxiety and upregulation of the $\alpha_{4}$ subunit of the $\mathrm{GABA}_{\mathrm{A}}$ receptor in the hippocampus (25). In high dosages, progesterone will cause sedation and even anesthesia in both humans and other animals $(8,15)$. It would therefore be of interest to examine levels of $\mathrm{GABA}_{\mathrm{A}}$ receptor active progesterone metabolites in blood samples and compare them with scores of mood symptoms.

One query is why the progesterone-induced cyclicity in symptoms is seen only in women without a history of PMS. One possible explanation for this differing pattern is that women with PMS are less sensitive to the effects of benzodiazepines and pregnanolone, especially during the late luteal phase $(15,16)$. In the present study, women with a history of PMS reacted in a similar manner, as they seemed to be less sensitive to progesterone than women without prior PMS. Studies using progesterone for the treatment of PMS have not been able to show a clinically relevant beneficial effect over placebo as shown in a recent systematic review (26). Earlier findings indicate that women with prior PMS respond with more severe negative mood symptoms than controls during the progestogen phase in HRT (3). The findings in this paper suggest that there exists a difference between natural progesterone and synthetic progestogens in that women with PMS react more than women without PMS on progestogens but not on progesterone. This difference might, however, be due to difference in dosage or potency of the substances more than a qualitatively different effect.

In conclusion, our study has shown that in women without a history of PMS progesterone causes similar negative effects on mood as progestogens. This finding is at odds with previous suggestions that progesterone differs from progestogens in its effects on mood. Furthermore, our findings indicate that the progesterone-induced negative mood effects may be dose-dependent. Apparently, the effect of progesterone is different in women with a history of PMS, as they seem to react less to the progesterone dosages tested compared with women without a history of PMS.

\section{Acknowledgements}

Agneta Andersson is acknowledged for skillful technical assistance. This work was supported by the Swedish Medical Research Council (proj. 4X-11198), Wallenberg Foundation, Umeå sjukvård, spjutspetsanslag, Visare Norr, Samverkansnämnden, Norra Regionen and by a grant from the EU-regional fund Objective 1.

\section{References}

1 Hammarbäck S, Bäckström T, Holst J, von Schoultz B \& Lyrenäs S. Cyclical mood changes as in the premenstrual tension syndrome during sequential estrogen-progestagen postmenopausal replacement therapy. Acta Obstetrica et Gynecologica Scandinavica 1985 64 393-397.

2 Magos AL, Brewster E, Sing R, O’Dowd TM \& Studd JWW. The effect of norethisterone in postmenopausal women on oestrogen therapy: a model for the premenstrual syndrome. British Journal of Obstetrics and Gynaecology 198693 1290-1296.

3 Björn I, Bixo M, Strandberg-Nöjd K, Nyberg S \& Bäckström T. Negative mood changes during hormone replacement therapy: a comparison between two progestogens. American Journal of Obstetrics and Gynecology 2000183 419-426.

4 Panay N \& Studd J. Progestogen intolerance and compliance with hormone replacement therapy in menopausal women. Human Reproduction Update 19973 159-171.

5 Schmidt PJ, Nieman LK, Danaceau MA, Adams LF \& Rubinow DR. Differential behavioral effects of gonadal steroids in women with and in those without premenstrual syndrome. New England Journal of Medicine 1998338 209-216.

6 Martorano JT, Ahlgrimm M \& Colbert T. Differentiating between natural progesterone and synthetic progestins: clinical implications for premenstrual syndrome and perimenopause management. Comprehensive Therapy 199824 336-339.

7 Majewska MD, Harrison NL, Schwartz RD, Barker JL \& Paul SM. Steroid hormone metabolites are barbiturate-like modulators of the GABA receptor. Science 1986232 1004-1007.

8 Bäckström T, Gee KW, Lan N, Sörensen M \& Wahlström G. Steroids in relation to epilepsy and anaesthesia. Ciba Foundation Symposium $1990153225-230$.

9 Mok WM \& Krieger NR. Evidence that 5 alpha-pregnan-3 alphaol-20-one is the metabolite responsible for progesterone anesthesia. Brain Research $199053342-45$.

10 Bitran D, Shiekh M \& Mcleod M. Anxiolytic effect of progesterone is mediated by the neurosteroid allopregnanolone at brain GABA(A) receptors. Journal of Neuroendocrinology 19957 $171-177$. 
11 Freeman E, Rickels K, Sondheimer SJ \& Polansky M. Ineffectiveness of progesterone suppository treatment for premenstrual syndrome. Journal of the American Medical Association $1990264349-353$.

12 Sampson GA. Premenstrual syndrome: a double-blind controlled trial of progesterone and placebo. British Journal of Psychiatry $1979135209-215$.

13 Bäckström T, Sanders D, Leask R, Davidson D, Warner P \& Bancroft J. Mood, sexuality, hormones, and the menstrual cycle. II. Hormone levels and their relationship to the premenstrual syndrome. Psychosomatic Medicine $1983 \mathbf{4 5}$ 503-507.

14 Hammarbäck S, Damber JE \& Bäckström T. Relationship between symptom severity and hormone changes in women with premenstrual syndrome. Journal of Clinical Endocrinology and Metabolism 198968 125-130.

15 Sundström I, Andersson A, Nyberg S, Ashbrook D, Purdy RH \& Bäckström T. Patients with premenstrual syndrome have a different sensitivity to a neuroactive steroid during the menstrual cycle compared to control subjects. Neuroendocrinology $1998 \mathbf{6 7}$ 126-138.

16 Sundström I, Nyberg S \& Bäckström T. Patients with premenstrual syndrome have reduced sensitivity to midazolam compared to control subjects. Neuropsycopharmacology 199717 370-381.

17 Cullberg J. Mood changes and menstrual symptoms with different gestogen/estrogen combinations. Acta Psychiatrica Scandinavica 1972 S236 3-86.

18 Spitzer RL, Williams JBW, Kroenke K, Linzer M, Verkoin de Gruy F III, Hahn SR et al. Utility of a new procedure for diagnosing mental disorders in primary care. Journal of the American Medical Association 1994272 1749-1756.

19 De Ligniers B, Dennerstein L \& Bäckström T. Influence of route of administration on progesterone metabolism. Maturitas 199521 $251-257$.
20 Holst J, Bäckström T, Hammarbäck S \& von Schoultz B. Progestogen addition during oestrogen replacement therapy - effects on vasomotor symptoms and mood. Maturitas 198911 13-20.

21 Sundström I, Nyberg S, Bixo M, Hammarbäck S \& Bäckström T. Treatment of premenstrual syndrome with gonadotropin-releasing hormone agonist in a low dose regimen. Acta Obstetrica et Gynecologica Scandinavica 1999 78 891-899.

22 Björn I, Bixo M, Strandberg-Nöjd K, Collberg P, Nyberg S, Sundström-Poromaa I et al. The impact of different doses of medroxyprogesterone acetate on symptoms in sequential hormone replacement therapy. Gynecological Endocrinology $2002161-8$

23 Fish EW, Faccidomo S, DeBold JF \& Miczek KA. Alcohol, allopregnanolone and aggression in mice. Psychopharmacology 2001153 473-483.

24 Beauchamp MH, Ormerod BK, Jhamandas K, Boegman RJ \& Beninger RJ. Neurosteroids and reward: allopregnanolone produces a conditioned place aversion in rats. Pharmacology, Biochemistry and Behavior 200067 29-35.

25 Gulinello M, Gong QH, Li X \& Smith SS. Short-term exposure to a neuroactive steroid increases alpha4 GABA(A) receptor subunit levels in association with increased anxiety in the female rat. Brain Research 2001910 55-66.

26 Wyatt K, Dimmock P, Jones P, Obhrai M \& O'Brien S. Efficacy of progesterone and progestogens in management of premenstrual syndrome: systematic review. British Medical Journal 2001323 $776-780$.

Received 4 November 2002

Accepted 21 January 2003 